\title{
The relationship between common mental disorders (CMDs), food insecurity and domestic violence in pregnant women during the COVID-19 lockdown in Cape Town, South Africa
}

\author{
Zulfa Abrahams $^{1}$ (D) Sonet Boisits ${ }^{1} \cdot$ Marguerite Schneider $^{1} \cdot$ Martin Prince $^{2} \cdot$ Crick Lund $^{1,2}$
}

Received: 21 October 2020 / Accepted: 9 July 2021 / Published online: 19 July 2021

(c) The Author(s) 2021

\begin{abstract}
Purpose We aimed to explore the relationship between common mental disorders (CMDs), food insecurity and experiences of domestic violence among pregnant women attending public sector midwife obstetric units and basic antenatal care clinics in Cape Town during the COVID-19 lockdown.

Methods Perinatal women, attending 14 healthcare facilities in Cape Town, were enrolled in the study during baseline data collection before the COVID-19 lockdown. During the lockdown period, fieldworkers telephonically contacted the perinatal women who were enrolled in the study and had provided contact details. The following data were collected from those who consented to the study: socio-demographic information, mental health assessment, food insecurity status and experiences of domestic violence. Poisson regression was used to model the associations of a number of risk factors with the occurrence of CMDs.

Results Of the 2149 women enrolled in the ASSET study, 885 consented to telephonic interviews. We found that $12.5 \%$ of women had probable CMDs and $43 \%$ were severely food insecure. Psychological distress increased significantly during the lockdown period, compared to before the COVID-19 outbreak. Using multivariate Poisson regression modelling, we showed that the risk of CMDs was increased in women who were severely food insecure or who experienced psychological or sexual abuse.

Conclusions This study provides evidence of the effect of the COVID-19 lockdown on the mental health status of perinatal women living in low-resource settings in Cape Town and highlights how a crisis such as the COVID-19 lockdown amplifies the psycho-social risk factors associated with CMDs in perinatal women.
\end{abstract}

Keywords COVID-19 $\cdot$ Maternal $\cdot$ Mental health $\cdot$ Depression $\cdot$ Food insecurity

\section{Introduction}

Common mental disorders (CMDs) such as depression and anxiety are highly prevalent during the perinatal period, especially in low- and middle-income countries where

Zulfa Abrahams

zulfa.abrahams@uct.ac.za

1 Department of Psychiatry and Mental Health, Alan J Flisher Centre for Public Mental Health, University of Cape Town, Building B, 46 Sawkins Road, Rondebosch, Cape Town, South Africa

2 Health Service and Population Research Department, Centre for Global Mental Health, Institute of Psychiatry, Psychology and Neuroscience, King's Global Health Institute, King's College London, London, UK approximately $19 \%$ of perinatal women develop depression [1], and approximately $34 \%$ develop anxiety [2]. In South Africa the prevalence is particularly high, with several studies reporting that one in every three pregnant women develop symptoms of depression [3-7], and one in every four pregnant women develop symptoms of anxiety [3, 8]. However, studies have also shown that the majority of women who experience mild to moderate symptoms of depression during their first and second trimester of pregnancy, show an improvement in symptoms during the remainder of the perinatal period, even without intervention [7, 9-11]. Studies in Cape Town, South Africa have identified several psychosocial risk factors for CMDs which include food insecurity, intimate partner violence, and lack of social support $[4,7$, 12]. 
The Coronavirus (COVID-19) outbreak was declared a global pandemic by the World Health Organisation on 11 March 2020 [13]. A few days later the President of South Africa announced that urgent and drastic measures were needed to manage the disease [14]. This included a travel ban, increased screening and testing and the closure of all schools. Two weeks later, a 35-day national lockdown came into effect $[15,16]$. This initial lockdown period became known as Alert Level-5 and required South Africans to stay home except for essential purposes. All nonessential activities were suspended until the end of April 2020, including the sale of alcohol [17]. During May 2020, South Africa moved to Alert Level-4, which resulted in a slight easing of restrictions. However, South Africans remained confined to their place of residence, except for those performing essential services [18]. On 1 June 2020, Alert Level-3 came into effect, further easing restrictions, which included unbanning the sale of alcohol and the opening of schools and some places of employment [19].

According to the World Health Organisation [20], experiencing fear, worry and distress is an understandable and normal response in the context of the COVID19 pandemic. The South African Depression and Anxiety Group (SADAG) reported that the COVID-19 lockdown in South Africa resulted in an increase in the number of calls from people feeling overwhelmed, anxious, worried and depressed. In an online survey completed between 2 and 15 April 2020, SADAG found that $65 \%$ of respondents were feeling stressed during the lockdown [21]. Pregnant women and mothers of young children are especially vulnerable to distress during the lockdown [7, 22]. Stressors highlighted include (1) the effects of social distancing and isolation, such as a lack of social support from family and friends, (2) financial difficulties, (3) the increased risk of intimate partner violence as women are forced to remain in close proximity to the perpetrator, (4) reduced antenatal and postnatal check-ups, and (5) partners' inability to participate in the birth $[23,24]$.

South Africa is a country characterised by high levels of inequality and poverty [25]. The majority of South Africans (55\%) live below the upper bound poverty line [26], with many living in overcrowded shacks with intergenerational families. Intimate partner violence rates are high and is thought to be associated with poverty and food insecurity [27]. The lockdown has been especially difficult for the already vulnerable groups living in poverty, as it has resulted in increased levels of unemployment, food insecurity [28] and domestic violence [29]. However, no studies have reported on effect of the COVID-19 crisis on the mental health of perinatal women in South Africa. As unemployment, food insecurity and domestic abuse is associated with CMDs, this study aims to explore the relationship between CMDs, food insecurity and experiences of violence among pregnant women attending public healthcare facilities in Cape Town during the COVID-19 lockdown.

\section{Methods}

\section{Setting}

This quantitative study was conducted with perinatal women attending 14 randomly selected midwife obstetric units (MOUs) or basic antenatal care (BANC) clinics in the Cape Metropolitan Health District in Cape Town. MOUs and BANC clinics are public sector antenatal and obstetric care facilities managed by the Western Cape Department of Health. The facilities are free at the point of contact and attended predominately by women living in low socioeconomic status communities. This study forms part of the bigger Health Systems Strengthening in sub-Saharan Africa (ASSET) study [30]—which includes a cluster randomised control trial (ISRTCN41483663) to evaluate an intervention to strengthen detection, referral and care for antenatal women with depression, anxiety and experiences of domestic violence in Cape Town.

In February and March 2020, 2149 perinatal women were enrolled in the ASSET study which occurred prior to the COVID-19 pandemic in South Africa. Data collected included a file review of their current Maternity Case Records (MCR) - the national stationery used to record all aspects of the pregnancy [31]. Information collected from the MCR included the patients' contact details, gestational and medical history, and results of a 3-question mental health screening questionnaire used to assess psychological distress [32]. The mental health screening questionnaire is routinely administered by health professionals during patients' first antenatal visit. MCRs of women who were pregnant (irrespective of gestation period) or had given birth in the past three months were included in the ASSET study's baseline data collection. As a result of the COVID-19 pandemic, data collection was suspended after completion of the baseline data collection, but before the intervention could begin. During the period when face-to-face data collection was not permitted, the study was opportunistically pivoted to focus on the impact of the COVID-19 lockdown on women already enrolled in the ASSET study.

\section{Testing procedures}

During June and July 2020 (Alert Level-3 lockdown), fieldworkers telephonically contacted the perinatal women who were enrolled in the ASSET study and had provided contact details and invited them to participate in a telephonic survey. Questionnaires were telephonically administered to perinatal women who consented to the study. Questionnaires were 
available in English, Afrikaans or IsiXhosa, and included (1) a socio-demographic questionnaire that was used to collect data on participants' age, obstetric information, relationship status, income status, and effect of the COVID-19 lockdown, (2) the same 3-question mental health screening questionnaire [32] that was administered by healthcare workers at patients' first clinic visit, (3) the Edinburgh Postnatal Depression Scale (EPDS) [33], (4) the Household Food Insecurity and Access Scale (HFIAS) [34], and (5) the short form of the Composite Abuse Scale (CAS-SF) [35].

The EPDS is commonly used as a screening tool in research settings and has been validated against the Diagnostic and Statistical Manual (DSM-IV) [36, 37] for depression and anxiety in a sample of postnatal women in South Africa $[33,38]$ with a cut-off of $\geq 13$ indicating a probable CMD. The questionnaire consists of 10 items with a sevenday recall period. The 3-question mental health screening questionnaire uses a two-week recall period and has been validated against the EPDS [32]. Both the 3-question mental health screening questionnaire and the EPDS asks about suicidality. Using a cut-point of $\geq 2$, this screening tool is able to identify perinatal women with psychological distress (sensitivity $=85.7 \%$; specificity $=92.9 \%$ ). The HFIAS was used to assess household food insecurity and hunger [34]. This 9-item scale measures the household's frequency of running out of food or eating inadequate amounts of food during the past 30 days. The CAS-SF [35] is a 15-item instrument that captures women's self-reported experience of physical, sexual and psychological abuse during the past 12 months.

\section{Data analysis}

Data analysis was carried out using STATA/SE statistical software package version 15.1 (StataCorp., College Station, TX, USA). All participants with incomplete data were excluded from the analysis. Variables were described using frequency and percentages, and associations measured using Chi-square tests. As the mental health screening questionnaire was administered in-person by healthcare workers, at patients' first clinic visit, and telephonically by trained fieldworkers during the lockdown, the Bland-Altman analysis was used to measure agreement between the two time-points $[39,40]$.

Psychological distress was calculated using the mental health screening questionnaire. Women who scored two or more on the questionnaire were classified as experiencing psychological distress. Univariate logistic regression analysis, using psychological distress as the outcome variable, was used to model the associations of several risk factors with the binary outcome variable. Household food security status was calculated [41] using the HFIAS to categorise households into four levels of household food insecurity experienced during the past 30 days: food secure, mildly food insecure, moderately food insecure and severely food insecure. The CAS-SF was used to categorise experiences of domestic violence during the past 12 months into physical, sexual and psychological abuse [35].

Poisson regression analysis was used to prevent overestimation of the risk [42]. Variables with a $p$ value of $<0.2$ in the univariate Poisson regression were entered in the multivariate model to generate adjusted risk ratios $[43,44]$.

\section{Ethical approval}

Ethical approval for the study was obtained from the Human Research Ethics Committee at the Faculty of Health Sciences, University of Cape Town (Ref No: 139/2018) and the Psychiatry, Nursing and Midwifery Research Ethics Subcommittee at Kings College London (Ref No: 17/18-7807). In addition, the Western Cape Department of Health approved the use of the research sites (Ref No: WC_201807_008). Consent forms were available in English, Afrikaans and isiXhosa. Participants provided informed consent after the procedure had been verbally explained to them. All participants were informed that they were free to withdraw from the study at any time without consequences. No financial incentives were provided for participating in the study.

\section{Results}

Data from MCRs were available for 2149 perinatal women (Supplementary Table). More than half the women $(n=1248 ; 58 \%)$ who were initially enrolled in the ASSET study, were not contactable due to missing or incorrect contact details. An additional 16 women declined to participate when contacted. In total, 1264 women were lost-to-followup (response rate $=41.2 \%)$. Gravidity $(p=0.672)$, pregnancy status $(p=0.097)$ and the results of a routinely administered mental health screening questionnaire $(p=0.199)$ were similar for those included in the study and those who were lost to follow-up. Significantly more young women aged 15-24 years were lost-to-follow-up ( $p=0.047)$.

Bivariate associations between CMD (measured using the EPDS) and the socio-demographic and psychological characteristics of participants are presented in Table 1 . The study sample consisted of 885 participants, of whom 110 (12.4\%) were classified as having a probable CMD and 775 $(87.6 \%)$ were not. Almost half the women were severely food insecure $(n=378)$, while more than half were unemployed $(n=475)$. The proportion of women with CMD significantly increased with increasing number of pregnancies $(p=0.017)$ and severity of food insecurity $(p<0.001)$. Significantly fewer women who had experienced their first pregnancy (20.9 vs. $30.2 \% ; p=0.045)$ and had already given 
Table 1 Bivariate associations between socio-demographic and psycho-social risk factors and probable CMD

\begin{tabular}{|c|c|c|c|c|}
\hline & $\begin{array}{l}\text { With CMD* } \\
(n=110 ; 12.4 \%) \\
n(\%)\end{array}$ & $\begin{array}{l}\text { Without CMD } \\
(n=775 ; 87.6 \%) \\
n(\%)\end{array}$ & Chi-square tests of independence & $\begin{array}{l}\text { Jonckheere-Terpstra } \\
\text { test for trend }\end{array}$ \\
\hline \multicolumn{5}{|l|}{ Age } \\
\hline $15-24$ years & $29(26.4)$ & $262(33.9)$ & $\chi^{2}(1)=2.498 ; p=0.114$ & \multirow[t]{4}{*}{$J=39,193 ; p=0.378$} \\
\hline $25-29$ years & $40(36.4)$ & $226(29.3)$ & $\chi^{2}(1)=2.297 ; p=0.130$ & \\
\hline 30-35 years & $28(25.4)$ & $187(24.2)$ & $\chi^{2}(1)=0.079 ; p=0.778$ & \\
\hline$>35$ years & $13(11.8)$ & 97 (12.6) & $\chi^{2}(1)=0.049 ; p=0.825$ & \\
\hline \multicolumn{5}{|l|}{ Gravidity } \\
\hline 1st pregnancy & $23(20.9)$ & $232(30.2)$ & $\chi^{2}(1)=4.007 ; p=0.045$ & \multirow[t]{3}{*}{$J=47,353 ; p=0.017$} \\
\hline 2-4 pregnancies & $74(67.3)$ & $483(62.8)$ & $\chi(1)=0.826 ; p=0.363$ & \\
\hline$>4$ pregnancies & $13(11.8)$ & $54(7.0)$ & $\chi^{2}(1)=3.144 ; p=0.076$ & \\
\hline \multicolumn{5}{|l|}{ Number of other children } \\
\hline 0 children & $36(33.0)$ & $294(38.2)$ & $\chi^{2}(1)=1.102 ; p=0.294$ & \multirow[t]{4}{*}{$J=44,602 ; p=0.226$} \\
\hline $1-2$ children & $59(54.1)$ & $396(51.5)$ & $\chi^{2}(1)=0.265 ; p=0.607$ & \\
\hline 3-4 children & $11(10.1)$ & $72(9.4)$ & $\chi^{2}(1)=0.059 ; p=0.808$ & \\
\hline$>4$ children & $3(2.8)$ & $7(0.9)$ & $\chi^{2}(1)=2.877 ; p=0.090$ & \\
\hline \multicolumn{5}{|l|}{ Pregnancy status } \\
\hline Postnatal & $70(63.6)$ & $568(74.1)$ & $\chi^{2}(1)=5.267 ; p=0.022$ & \\
\hline Pregnant & $34(30.9)$ & $192(25.0)$ & $\chi^{2}(1)=1.737 ; p=0.188$ & \\
\hline Miscarriage/ Stillbirth & $6(5.5)$ & $7(0.9)$ & $\chi^{2}(1)=13.590 ; p<0.001$ & \\
\hline Unplanned pregnancy & $75(69.4)$ & $477(62.6)$ & $\chi^{2}(1)=0.912 ; p=0.167$ & \\
\hline No partner & $20(18.4)$ & $86(11.4)$ & $\chi^{2}(1)=4.355 ; p=0.037$ & \\
\hline Psychological distress at first clinic visit** & $5(9.1)$ & $12(2.5)$ & $\chi^{2}(1)=7.168 ; p=0.007$ & \\
\hline Anxiety/worry about getting infected $* * *$ & $100(90.9)$ & $640(83.1)$ & $\chi^{2}(1)=4.368 ; p=0.037$ & \\
\hline \multicolumn{5}{|l|}{ Employment status prior to the lockdown } \\
\hline Employed & $44(40.0)$ & $304(39.5)$ & $\chi^{2}(1)=0.011 ; p=0.917$ & \\
\hline Unemployed & $58(52.7)$ & $417(54.1)$ & $\chi^{2}(1)=0.079 ; p=0.799$ & \\
\hline Student & $8(7.3)$ & $49(6.4)$ & $\chi^{2}(1)=0.131 ; p=0.717$ & \\
\hline Increased crime in community $* * * *$ & $37(33.6)$ & $172(22.5)$ & $\chi^{2}(1)=6.621 ; p=0.010$ & \\
\hline Increased domestic violence $* * *$ & $5(4.6)$ & $23(3.0)$ & $\chi^{2}(1)=0.783 ; p=0.376$ & \\
\hline Decreased income ${ }^{* * *}$ & $80(72.7)$ & $496(64.6)$ & $\chi^{2}(1)=2.828 ; p=0.093$ & \\
\hline Decreased amount of food in household $* * *$ & $98(89.1)$ & $551(71.6)$ & $\chi^{2}(1)=15.282 ; p<0.001$ & \\
\hline \multicolumn{5}{|l|}{ Food security status $* * *$} \\
\hline Food secure & $7(6.5)$ & $167(21.7)$ & $\chi^{2}(1)=13.858 ; p<0.001$ & \multirow[t]{4}{*}{$J=54,498 ; p<0.001$} \\
\hline Mildly food insecure & $6(5.6)$ & $75(9.8)$ & $\chi^{2}(1)=1.999 ; p=0.157$ & \\
\hline Moderately food insecure & $22(20.4)$ & $221(28.8)$ & $\chi^{2}(1)=3.337 ; p=0.068$ & \\
\hline Severely food insecure & 73 (67.6) & $305(39.7)$ & $\chi^{2}(1)=30.000 ; p<0.001$ & \\
\hline \multicolumn{5}{|l|}{ Experiences of abuse $\mathrm{e}^{* * *}$} \\
\hline Psychological abuse & $36(34.3)$ & $101(13.4)$ & $\chi^{2}(1)=30.005 ; p<0.001$ & \\
\hline Physical abuse & $33(31.1)$ & $88(11.7)$ & $\chi^{2}(1)=29.112 ; p<0.001$ & \\
\hline Sexual abuse & $8(7.5)$ & $6(0.8)$ & $\chi^{2}(1)=26.667 ; p<0.001$ & \\
\hline
\end{tabular}

*Probable common mental disorder (CMD), scored $\geq 13$ on the Edinburgh Postnatal Depression Scale (EPDS)

$* *$ Scored $\geq 2$ on routinely administered mental health screening questionnaire

***During the Covid-19 lockdown

birth at follow-up had a probable CMD (63.6 vs. 74.1\%; $p<0.022$ ).

Significantly more women with a probable CMD had experienced a previous miscarriage or stillbirth (5.5 vs.
$0.9 \% ; p<0.001)$, did not have a partner (18.4 vs. $11.4 \%$; $p=0.037)$, experienced psychological distress at the first clinic visit ( 9.1 vs. $2.5 \% ; p=0.007$ ), experienced anxiety about being infected with the COVID-19 virus (90.9 vs. 
$83.1 \% ; p=0.037)$, experienced an increase in crime in their community (33.6 vs. $22.5 \% ; p=0.010$ ) and a decrease in food available in the household ( 89.1 vs. $71.6 \% ; p<0.001)$ during the lockdown, were severely food insecure (67.6 vs. $39.7 \% ; p<0.001)$ and experienced psychological (34.3 vs. $13.4 \%$; $p<0.001$ ), physical (31.1 vs. $11.7 \% ; p<0.001)$ or sexual abuse ( 7.5 vs. $0.8 \% ; p<0.001)$, compared to women without CMD.

A comparison of the results of the routinely administered mental health screening tool is presented in Table 2. Five hundred and fifty-five participants completed the screening questionnaire at their first clinic visit and during the lockdown. During the lockdown, the proportion of women who felt unable to stop worrying or thinking too much increased more than three-fold (12-40\%), while the number of women who felt down, depressed or hopeless increased by six times $(5-30 \%)$. There was no change in the number or proportion of women who felt suicidal. Significantly more women experienced psychological distress during the lockdown, compared to their first clinic visit (3.1 vs. 26.2\%; $p<0.001$ ). Using the EPDS as the gold standard, a cut-point of $\geq 2$ on the mental health screening questionnaire was able to correctly classify $88.6 \%$ of participants (sensitivity $=0.71$; specificity $=0.91$ ).

Univariate logistic regression of risk factors against the outcome, psychological distress at the first clinic visit and during the lockdown is presented in Table 3. Several MCRs contained incomplete mental health screening questionnaires, resulting in fewer participants with a measure of psychological distress at the first clinic visit compared to during the lockdown. Only experiences of psychological abuse were significantly associated with psychological distress at the first clinic visit [Odds ratio (OR) 3.65; 95\% Confidence interval (CI) 1.26-10.55]. The odds of experiencing psychological distress during the lockdown were significantly associated with: more than four previous pregnancies (OR 1.74; 95\% CI 1.04-2.93); a previous miscarriage or stillbirth (OR 9.72; 95\% CI 2.65-35.66); no partner (OR 2.23; 95\% CI 1.47-3.40); an increase in crime in their community (OR $2.01 ; 95 \% \mathrm{CI}$ 1.43-2.80); less income during the lockdown (OR 1.68; 95\% CI 1.20-2.35); less food in the household during the lockdown (OR 2.24; 95\% CI 1.52-3.31); severe food insecurity during the lockdown (OR 2.39; 95\% CI 1.76-3.25); psychological (OR 3.05; 95\% CI 2.09-4.46) physical (OR 2.77 ; 95\% CI 1.86-4.11) or sexual (OR 7.30; 95\% CI 2.27-23.53) abuse in the past 12 months.

The relative risk of experiencing a probable CMD is shown in Table 4 . In the univariate model, having already given birth [Risk ratio $(\mathrm{RR})=0.66$; 95\% CI 0.44-0.97] was negatively associated with experiencing a probable CMD, while having had a previous miscarriage or stillbirth (RR 3.83; 95\% CI 1.68-8.73), experiencing increased crime in the community (RR 1.62; 95\% CI 1.09-2.40), experiencing psychological distress at the first clinic visit (RR 3.09; 95\% CI 1.23-7.76), being severely food insecure (RR 2.75 ; 95\% CI 1.84-4.11) or experiencing physical (RR 2.76; 95\% CI 1.83-4.16), psychological (RR 2.75; 95\% CI 1.84-4.11]) or sexual (RR 4.96; 95\% CI 2.41-10.20) abuse was associated with a probable CMD.

In the multivariate model, women were at increased risk of a probable CMD if they had a previous miscarriage or stillbirth (RR 3.60; 95\% CI 1.15-11.21), experienced severe food insecurity (RR 3.01; 95\% CI 1.60-5.65), or experienced psychological abuse (RR 3.38; 95\% CI $1.25-4.54$ ) or sexual abuse (RR 2.53 ; 95\% CI 1.03-6.24).

Table 2 Comparison of the results of the routinely administered mental health screening questionnaire measuring psychological distress before and during the lockdown $(n=555)$

\begin{tabular}{|c|c|c|c|c|}
\hline & $\begin{array}{l}\text { At the } 1 \text { st clinic visit } \\
n(\%)\end{array}$ & $\begin{array}{l}\text { During the lockdown } \\
n(\%)\end{array}$ & Bland-Altman tests & Chi-square test \\
\hline $\begin{array}{l}\text { Question 1: have you on some or most days felt unable to } \\
\text { stop worrying or thinking too much? }\end{array}$ & $66(11.9)$ & $221(39.8)$ & $r=0.392 ; p<0.001$ & $\begin{array}{l}\chi^{2}(1)=160.790 \\
p<0.001\end{array}$ \\
\hline $\begin{array}{l}\text { Question 2: have you on some or most days felt down, } \\
\text { depressed or hopeless? }\end{array}$ & $27(4.9)$ & $168(30.4)$ & $r=0.640 ; p<0.001$ & $\begin{array}{l}\chi^{2}(1)=144.048 \\
p<0.001\end{array}$ \\
\hline $\begin{array}{l}\text { Question 3: have you on some or most days had thoughts } \\
\text { and plans to harm yourself or commit suicide? }\end{array}$ & $10(1.8)$ & $10(1.8)$ & $r=0.00 ; p=1.0$ & $\begin{array}{l}\chi^{2}(1)=0.0719 \\
p=0.789\end{array}$ \\
\hline Psychological distress* & $17(3.1)$ & $230(26.2)$ & $r=0.720 ; p<0.001$ & $\begin{array}{l}\chi^{2}(1)=126.817 \\
p<0.001\end{array}$ \\
\hline Mental Health Score** $[$ mean $( \pm S D)]$ & $0.18( \pm 0.49)$ & $0.72( \pm 0.86)$ & $r=0.505 ; p<0.001$ & $\begin{array}{l}t=12.985 \\
p<0.001^{* * *}\end{array}$ \\
\hline
\end{tabular}

$*$ Score of $\geq 2$ on the mental health screening questionnaire

**Sum of questions $1-3(\min =0 ; \max =3)$

$* * * t$ test 
Table 3 Univariate logistic regression models: factors associated with psychological distress at the first clinic visit and during the lockdown
Psychological distress*: 1st Psychological clinic visit $(n=543) \quad$ distress: lockdown $(n=869)$

Odds ratio ( $95 \%$ confidence interval)

\begin{tabular}{|c|c|c|}
\hline \multicolumn{3}{|l|}{ Age } \\
\hline $15-24$ years & $1.23(0.71-2.16)$ & $0.61(0.44-0.86)$ \\
\hline $25-29$ years & $0.86(0.44-1.66)$ & $1.21(0.88-1.68)$ \\
\hline $30-35$ years & $0.97(0.50-1.89)$ & $1.33(0.95-1.87)$ \\
\hline$>35$ years & $0.77(0.23-2.19)$ & $1.06(0.68-1.66)$ \\
\hline \multicolumn{3}{|l|}{ Gravidity } \\
\hline 1st pregnancy & $0.63(0.33-1.21)$ & $0.63(0.44-0.89)$ \\
\hline 2-4 pregnancies & $1.56(0.86-2.81)$ & $1.23(0.89-1.68)$ \\
\hline$>4$ pregnancies & $0.86(0.31-2.44)$ & $1.74(1.04-2.93)$ \\
\hline \multicolumn{3}{|l|}{ Number of children } \\
\hline 0 children & $0.81(0.36-1.82)$ & $0.61(0.44-0.86)$ \\
\hline 1-2 children & $0.72(0.30-1.70)$ & $1.21(0.88-1.68)$ \\
\hline 3-4 children & $0.34(0.81-1.40)$ & $1.33(0.95-1.87)$ \\
\hline$>4$ children & $1.76(0.96-3.21)$ & $1.06(0.68-1.66)$ \\
\hline \multicolumn{3}{|l|}{ Pregnancy status } \\
\hline Post-birth & $1.46(0.82-2.63)$ & $0.88(0.63-1.123)$ \\
\hline Pregnant & $0.68(0.39-1.22)$ & $0.93(0.66-1.31)$ \\
\hline Miscarriage/Stillbirth & & $9.72(2.65-35.66)$ \\
\hline Unplanned pregnancy & $1.42(0.49-4.09)$ & $1.28(0.93-1.76)$ \\
\hline No partner & $1.16(0.26-5.21)$ & $2.23(1.47-3.40)$ \\
\hline \multicolumn{3}{|l|}{ Employment status prior to the lockdown } \\
\hline Employed & $0.73(0.27-2.02)$ & $0.81(0.59-1.10)$ \\
\hline Unemployed & $1.33(0.50-3.55)$ & $1.32(0.97-1.78)$ \\
\hline Student & $1.05(0.13-8.17)$ & $0.74(0.38-1.42)$ \\
\hline Increased crime in community** & & $2.01(1.43-2.80)$ \\
\hline Increased domestic violence** & & $3.96(1.84-8.52)$ \\
\hline Decreased income** & & $1.68(1.20-2.35)$ \\
\hline Decreased amount of food in household** & & $2.24(1.52-3.31)$ \\
\hline \multicolumn{3}{|l|}{ Food security status during the past 30 days** } \\
\hline Food secure & & $0.33(0.20-0.53)$ \\
\hline Mildly food insecure & & $0.67(0.38-1.19)$ \\
\hline Moderately food insecure & & $0.82(0.58-1.16)$ \\
\hline Severely food insecure & & $2.39(1.76-3.25)$ \\
\hline \multicolumn{3}{|c|}{ Experiences of abuse during the past 12 months $* *$} \\
\hline Psychological abuse & & $3.05(2.09-4.46)$ \\
\hline Physical abuse & & $2.77(1.86-4.11)$ \\
\hline Sexual abuse & & $7.30(2.27-23.53)$ \\
\hline
\end{tabular}

*Scored $\geq 2$ on mental health screening questionnaire

**During the Covid-19 lockdown

\section{Discussion}

As little is known about the effects of the COVID-19 lockdown on known risk factors for perinatal depression, this study explored the relationship between the mental health status of perinatal women, and their experiences of food insecurity and domestic violence during the COVID-19 lockdown. We found that $12 \%$ of women had probable CMDs and $43 \%$ were severely food insecure. Levels of psychological distress increased significantly during the lockdown period, compared to before the COVID-19 outbreak in South Africa. While we did not find an increase in women who felt suicidal, significantly more women reported feeling anxious and depressed. Using multivariate Poisson 
Table 4 Poisson regression model: factors associated with probable CMDs

\begin{tabular}{|c|c|c|}
\hline & Unadjusted model & Multivariate model* \\
\hline & \multicolumn{2}{|c|}{ Risk ratio (95\% confidence interval) } \\
\hline 1st pregnancy (ref: $>4$ pregnancies) & $0.65(0.41-1.02)$ & $0.58(0.31-1.09)$ \\
\hline 2-4 pregnancies (ref: $>4$ pregnancies) & $1.19(0.80-1.77)$ & \\
\hline Post-birth (ref: pregnant) & $0.66(0.44-0.97)$ & \\
\hline Miscarriage/stillbirth (ref: pregnant) & $3.83(1.68-8.73)$ & $3.60(1.15-11.21)$ \\
\hline No partner & $1.61(0.99-2.62)$ & \\
\hline Increased crime in community** & $1.62(1.09-2.40)$ & $1.50(0.82-2.71)$ \\
\hline Psychological distress at first clinic visit ${ }^{* * *}$ & $3.09(1.23-7.76)$ & \\
\hline Mildly food insecure ${ }^{* * *}$ (ref: food secure) & $0.58(0.25-1.31)$ & \\
\hline Moderately food insecure ${ }^{* * *}$ (ref: food secure) & $0.67(0.42-1.06)$ & \\
\hline Severely food insecure ${ }^{* * *}$ (ref: food secure) & $2.75(1.84-4.11)$ & $3.01(1.60-5.65)$ \\
\hline Physical abuse & $2.76(1.83-4.16)$ & \\
\hline Psychological abuse & $2.75(1.84-4.11)$ & $2.38(1.25-4.54)$ \\
\hline Sexual abuse & $4.96(2.41-10.20)$ & $2.53(1.03-6.24)$ \\
\hline
\end{tabular}

regression modelling, we showed that the risk of CMD was almost three times greater in women who were severely food insecure, or who experienced psychological or sexual abuse. Importantly, we found strong associations between certain risk factors (having more than four pregnancies or a previous miscarriage or stillbirth, experiencing increased crime in the community, decreased income or less food in the household, severe food insecurity, or any form of abuse) and psychological distress during the COVID-19 lockdown.

Compared to other studies in South Africa [3, 4, 7, 12], our study found a relatively low prevalence of CMDs (12.5\% vs. $15-40 \%$ ) in pregnant women during the COVID-19 lockdown, given that more than $80 \%$ of those interviewed reported feeling anxious about getting infected, more than $60 \%$ were unemployed and fewer than $20 \%$ of households were food secure. This is contrary to a recent review assessing the psychological impact of the lockdown, which found that being quarantined resulted in a higher prevalence of psychological problems such as depression and anxiety, especially in those who were pregnant or had young children [45]. The review further suggests that while stressors including experiencing financial loss, fear of infection and stigma from others increased psychological problems during quarantine, the longer the duration of quarantine, the greater the psychological distress. Possible explanations for the low prevalence found in our study could be due to the short length of quarantine as data collection began approximately five weeks into the lockdown, and the consequences of the financial and other losses may not yet have been felt.

We found that the proportion of women experiencing psychological distress during the lockdown was higher than those who were distressed at their first clinic visit. While the lack of a control group makes it difficult to draw strong conclusions about the effect off the COVID-19 lockdown on symptoms of depression and anxiety, evidence from a longitudinal study in the same population [7] indicates that symptoms of depression detected early in pregnancy tend to abate during the course of pregnancy and the first year of the baby's life. Our findings indicate the opposite, namely an increase in prevalence of psychological distress. As there were no other significant societal level events during this period that may have contributed to such an increase, we believe there is some support for the hypothesis that it was due to the COVID-19 lockdown. We did not observe a change in the number or proportion of women who felt suicidal. This is not out of keeping with other research; when examining studies reporting on suicidal thoughts and behaviour during pregnancy and the postpartum period, several studies have reported a decreased risk [46-48].

In LMIC, poverty is a well-documented risk factor for CMDs, especially during the perinatal period $[49,50]$. The relationship is considered to be complex and bidirectional with several social issues interacting [51, 52]. Similar strong associations between food insecurity and CMDs have been consistently reported $[4,53,54]$. In a particularly low-resource setting in Cape Town, the odds of depression was five times greater in perinatal women who were food insecure compared to those who were food secure, while the odds of experiencing food insecurity was four times greater in women who were depressed compared to those who were not [4]. Our study found that being severely food insecure doubled the odds of CMDs during the COVID-19 lockdown, and that $80 \%$ of participants reported experiencing various levels of food insecurity. The high prevalence 
of food insecurity can be attributed to the COVID-19 lockdown. During April and May 2020, when South Africa was at Alert Level-4 and Level-5 of the lockdown, all nonessential services were halted. This resulted in high levels of unemployment, affecting the most vulnerable workers, who were low-skilled and less educated, the most [55]. Six weeks into the lockdown, Statistics South Africa, using an online survey, found that $4.3 \%$ of respondents reported experiencing hunger during the month prior to the lockdown, while $7 \%$ experienced hunger during the lockdown [56]. This is likely being under reported as those living in poverty and experiencing hunger would be unlikely to have access to a web-based survey. In our already vulnerable group of perinatal women living in low-resource settings in Cape Town, we found that more than $40 \%$ were severely food insecure. This translates to $40 \%$ of perinatal women living in households where they were eating fewer meals than needed, lacked the resources to acquire more food, went to sleep hungry or went a whole day and night without eating [41].

We found that the risk of CMDs was almost three times greater in women experiencing psychological or sexual abuse. However, we found quite a low prevalence of domestic abuse in our study compared to findings in similar populations $[57,58]$. We found that $15 \%$ of participants reported experiencing psychological abuse, $14 \%$ reported experiencing physical abuse and less than $2 \%$ reported experiencing sexual abuse. Malan et al. [57], using the same 12-month recall period as in our study, reported that more than $40 \%$ of perinatal women experienced psychological abuse and 25\% experienced sexual abuse. Schneider et al. [58] reported that $13.9 \%$ of pregnant women reported experiencing physical and/or sexual abuse. The lower prevalence in our study may be attributed to the telephonic data collection method used and the fact that the interviews were conducted during the lockdown period when the majority of South Africans were still confined to their homes. Participants may have under reported their experiences of abuse as their perpetrators were likely able to hear their responses to the interview questions.

Our study has a number of limitations. Selection bias may be present as more than half the women were not contactable. While levels of psychological distress before the lockdown were similar in those who were and were not contactable, it is possible that some women could not be contacted due to factors associated with socio-economic adversity, such as not being able to afford a cell phone. This study could therefore have under reported the level of unemployment and food insecurity, as well as the associated adverse outcomes such as CMDs and domestic violence. We did not have a control group, making it difficult to draw strong conclusions about the effect of the COVID-19 lockdown on depression and anxiety. We used only quantitative questionnaires which did not allow us to fully explore the perceived causes of CMDs, food insecurity and experiences of violence. We were only able to compare psychological distress as measured by a brief screening tool across the two time points, instead of using a validated tool such as the EPDS. In addition, the first screening was done at healthcare facilities by healthcare workers, while the second screening was telephonically administered by fieldworkers. The prevalence of CMDs could be under reported in the first screening, as patients may not have been willing to disclose personal information regarding their mood to healthcare workers whose primary role is perceived to be providing physical care rather than emotional support. Bland-Altman analysis has been used to account for the mean difference in measurement methods. We started data collection on the same day that the alcohol ban was lifted, which did not give us enough time to measure the impact of alcohol sales on domestic violence.

Further research is needed (1) to understand the coping mechanisms used by perinatal women to mitigate the stress of living in households with high levels of unemployment, food insecurity and domestic violence; (2) to investigate the effect that lifting the alcohol ban has had on domestic violence; and (3) to examine longer term trends in mental health, domestic abuse and food insecurity among perinatal women during the COVID-19 lockdown.

\section{Conclusion}

This study provides evidence of the effect of the COVID-19 lockdown on the mental health status of perinatal women living in low-resource settings in Cape Town. The COVID19 lockdown triggered high levels of unemployment and increased the prevalence of food insecurity, resulting in an increase in psychological distress being experienced during the lockdown, compared to before the lockdown. Our findings highlight how a crisis such as the COVID-19 lockdown amplified the psycho-social risk factors associated with CMDs in perinatal women.

Supplementary Information The online version contains supplementary material available at https://doi.org/10.1007/s00127-021-02140-7.

Acknowledgements We are grateful to the women who participated in the study for generously giving their time and energy to complete interviews.

Author contributions ZA and CL proposed the study. All authors provided input in the design of the study. ZA performed the data analysis and prepared the first draft of the manuscript. All authors reviewed the manuscript and provided input. All authors approved the final version of the manuscript.

Funding The ASSET study is funded by the National Institute for Health Research (NIHR) Global Health Research Unit on Health 
System Strengthening in Sub-Saharan Africa, King's College London (GHRU 16/136/54).

Availability of data and materials The dataset included for the analyses within this manuscript can be obtained on request from the corresponding author.

\section{Declarations}

Conflict of interest The authors have no competing interests to declare.

Ethics approval Ethical approval for the study was obtained from the Human Research Ethics Committee at the Faculty of Health Sciences, University of Cape Town (139/2018) and the Psychiatry, Nursing and Midwifery Research Ethics Subcommittee at Kings College London (17/18-7807). In addition, the Western Cape Department of Health approved the use of the research sites (WC_201807_008). Participants provided informed consent after the procedure had been verbally explained to them.

Open Access This article is licensed under a Creative Commons Attribution 4.0 International License, which permits use, sharing, adaptation, distribution and reproduction in any medium or format, as long as you give appropriate credit to the original author(s) and the source, provide a link to the Creative Commons licence, and indicate if changes were made. The images or other third party material in this article are included in the article's Creative Commons licence, unless indicated otherwise in a credit line to the material. If material is not included in the article's Creative Commons licence and your intended use is not permitted by statutory regulation or exceeds the permitted use, you will need to obtain permission directly from the copyright holder. To view a copy of this licence, visit http://creativecommons.org/licenses/by/4.0/.

\section{References}

1. Woody C, Ferrari A, Siskind D, Whiteford H, Harris M (2017) A systematic review and meta-regression of the prevalence and incidence of perinatal depression. J Affect Disord 219:86-92

2. Dennis C, Falah-Hassani K, Shiri R (2017) Prevalence of antenatal and postnatal anxiety: systematic review and meta-analysis. Br J Psychiatry 210:315-323

3. Redinger S, Norris S, Pearson R, Richter L, Rochat T (2018) First trimester antenatal depression and anxiety: prevalence and associated factors in an urban population in Soweto, South Africa. J Dev Orig Health Dis 9:30-40

4. Abrahams Z, Lund C, Field S, Honikman S (2018) Factors associated with household food insecurity and depression in pregnant South African women from a low socio-economic setting: a crosssectional study. Soc Psychiatry Psychiatr Epidemiol 53:363

5. Hartley M, Tomlinson M, Greco E, Comulada WS, Stewart J, Le Roux I, Mbewu N, Rotheram-Borus MJ (2011) Depressed mood in pregnancy: prevalence and correlates in two Cape Town periurban settlements. Reprod Health 8:9

6. Manikkam L, Burns JK (2012) Antenatal depression and its risk factors: an urban prevalence study in KwaZulu-Natal. S Afr Med J 102:940-944

7. Garman EC, Schneider M, Lund C (2019) Perinatal depressive symptoms among low-income South African women at risk of depression: trajectories and predictors. BMC Pregnancy Childbirth $19 \cdot 202$
8. van Heyningen T, Honikman S, Myer L, Onah MN, Field S, Tomlinson M (2017) Prevalence and predictors of anxiety disorders amongst low-income pregnant women in urban South Africa: a cross-sectional study. Arch Women's Men Health 20:765-775

9. Lee C, Stroo M, Fuemmeler B, Malhotra R, Østbye T (2014) Trajectories of depressive symptoms over 2 years postpartum among overweight or obese women. Womens Health Issues 24:559-566

10. Christensen AL, Stuart EA, Perry DF, Le H (2011) Unintended pregnancy and perinatal depression trajectories in low-income, high-risk Hispanic immigrants. Prev Sci 12:289-299

11. Mora PA, Bennett IM, Elo IT, Mathew L, Coyne JC, Culhane JF (2009) Distinct trajectories of perinatal depressive symptomatology: evidence from growth mixture modeling. Am J Epidemiol 169:24-32

12. van Heyningen T, Myer L, Onah M, Tomlinson M, Field S, Honikman S (2016) Antenatal depression and adversity in urban South Africa. J Affect Disord 203:121-129

13. WHO (2020) WHO Director-general's opening remarks at the media briefing on COVID-19-11 March 2020. In: World Health Organisation. https://www.npr.org/sections/https://www.who.int/ $\mathrm{dg} / \mathrm{speeches/detail/who-director-general-s-opening-remarks-at-}$ the-media-briefing-on-covid-19---11-march-2020/2020/03/11/ 814474930/coronavirus-covid-19-is-now-officially-a-pandemicwho-says. Accessed 28 Apr 2020

14. South African Government (2020) President Cyril Ramaphosa: Measures to combat Coronavirus COVID-19 epidemic. South African Government. https://www.gov.za/speeches/statementpresident-cyril-ramaphosa-measures-combat-covid-19-epide mic-15-mar-2020-0000. Accessed 28 Apr 2020

15. South African Government (2020) President cyril ramaphosa: escalation of measures to combat coronaviris covid-19 pandemic. South African Government. https://www.gov.za/speeches/presi dent-cyril-ramaphosa-escalation-measures-combat-coronaviruscovid-19-pandemic-23-mar. Accessed 28 Apr 2020

16. South African Government (2020) Preseident cyril ramaphosa: extension of coronavirus covid-19 lockdown to the end of April. South African Government. https://www.gov.za/speeches/presi dent-cyril-ramaphosa-extension-coronavirus-covid-19-lockdownend-april-9-apr-2020-0000. Accessed 28 Apr 2020

17. National Department of Health (2020) COVID-19 risk adjusted strategy. In: https://sacoronavirus.co.za/covid-19-risk-adjustedstrategy/. Accessed 4 Sept 2020

18. South African Government (2020) Disaster management act: regulations: alert level 4 during the coronavirus covid-19 lockdown. South African Government. https://www.gov.za/coronavirus/alertlevel-4. Accessed 4 Sept 2020

19. South African Government (2020) Disaster management act: regulations: alert level 3 during the coronaviris covid-19 lockdown. South African Government. https://www.gov.za/coronavirus/alertlevel-3. Accessed 4 Sept 2020

20. World Health Organisation (2020) Mental health and COVID-19. World Health Organisation. https://www.who.int/teams/mentalhealth-and-substance-use/covid-19. Accessed 7 Sept 2020

21. The South African Depression and Anxiety Group (2020) SADAG's online survey findings on COVID-19 and mental health. The South African depression and anxiety group. http://www.sadag. org/. Accessed 28 Apr 2020

22. Caparros-Gonzalez RA, Alderdice F (2020) The COVID-19 pandemic and perinatal mental health. J Reprod Infant Psychol 38:223-225

23. Holmes EA, O'Connor RC, Perry VH, Tracey I, Wessely S, Arseneault L, Ballard C, Christensen H, Silver RC, Everall I (2020) Multidisciplinary research priorities for the COVID-19 pandemic: a call for action for mental health science. Lancet Psychiatry $7: 547-560$ 
24. Yang H, Wang C, Poon L (2020) Novel coronavirus infection and pregnancy. Ultrasound Obstet Gynecol 55:435-437

25. Posel D, Rogan M (2019) Inequality, social comparisons and income aspirations: Evidence from a highly unequal country. $\mathrm{J}$ Hum Dev Capab 20:94-111

26. Statistics South Africa (2017) Poverty trends in South Africa: an examination of absolute poverty between 2006 and 2015 .

27. Gibbs A, Jewkes R, Willan S, Washington L (2018) Associations between poverty, mental health and substance use, gender power, and intimate partner violence amongst young (18-30) women and men in urban informal settlements in South Africa: a cross-sectional study and structural equation model. PLoS ONE 13:e0204956

28. Davis R (2020) The biggest lockdown threat: hunger, hunger, everywhere. Daily Maverick. https://www.dailymaverick.co.za/artic le/2020-04-17-the-biggest-lockdown-threat-hunger-hunger-every where/. Accessed 28 Apr 2020

29. Dartnell E, Gebers A, Pino C, Pino A (2020) Domestic violence during COVID-19: are we asking the right questions? United Nations Office for the Coordination of Humanitarian Relief (OCHA). https://reliefweb.int/report/south-africa/domestic-viole nce-during-covid-19-are-we-asking-right-questions. Accessed 7 Sept 2020

30. ASSET (2020) Maternal mental health and violence against women in South Africa. King's Global Health Institute. https:// healthasset.org/wp6/. Accessed 29 Sept 2020

31. Department of Health (2018) Maternity case record. Western cape Government. https://pmhp.za.org/wp-content/uploads/ Western-Cape-Maternity-Case-Record-Version-19-June-2018. pdf. Accessed 23 Mar 2020

32. Abrahams Z, Schneider M, Field S, Honikman S (2019) Validation of a brief mental health screening tool for pregnant women in a low socio-economic setting. BMC Psychol 7:77

33. Cox JL, Holden JM, Sagovsky R (1987) Detection of postnatal depression: development of the 10-item Edinburgh postnatal depression scale. Br J Psychiatry 150:782-786

34. Castell GS, Rodrigo CP, de la Cruz J, Ngo BJA (2015) Household food insecurity access scale (HFIAS). Nutr Hosp 31:272-278

35. Ford-Gilboe M, Wathen CN, Varcoe C, MacMillan HL, ScottStorey K, Mantler T, Hegarty K, Perrin N (2016) Development of a brief measure of intimate partner violence experiences: the composite abuse scale (revised)—short form (CASR-SF). BMJ Open 6:e012824

36. Frances AJ, Widiger TA, Pincus HA (1989) The development of DSM-IV. Arch Gen Psychiatry 46:373-375

37. Sheehan D, Lecrubier Y, Sheehan KH, Sheehan K, Amorim P, Janavs J, Weiller E, Hergueta T, Baker R, Dunbar G (1998) Diagnostic psychiatric interview for DSM-IV and ICD-10. J Clin Psychiatr 59:22-33

38. Lawrie T, Hofmeyr G, De Jager M, Berk M (1998) Validation of the Edinburgh postnatal depression scale on a cohort of South African women. S Afr Med J 88:1340-1344

39. Bunce C (2009) Correlation, agreement, and Bland-Altman analysis: statistical analysis of method comparison studies. Am J Ophthal 148:4-6

40. Bland JM, Altman DG (1999) Measuring agreement in method comparison studies. Stat Methods Med Res 8:135-160

41. Coates J, Swindale A, Bilinsky P (2007) Household Food Insecurity Access Scale (HFIAS) for measurement of food access: Indicator guide. Food and nutrition technical assistance project
(FANTA). http://www.fao.org/fileadmin/user_upload/eufaofsi4dm/doc-training/hfias.pdf. Accessed 24 Aug 2020

42. Zou G (2004) A modified poisson regression approach to prospective studies with binary data. Am J Epidemiol 159:702-706

43. Cohen J, Cohen P, West SG, Aiken LS (2013) Applied multiple regression/correlation analysis for the behavioral sciences. Routledge, England

44. Famoye F, Rothe DE (2003) Variable selection for Poisson regression model. J Modern Appl Stat Methods 2:11

45. Brooks SK, Webster RK, Smith LE, Woodland L, Wessely S, Greenberg N, Rubin GJ (2020) Rapid review. Lancet 395:912-920

46. Marzuk PM, Tardiff K, Leon AC, Hirsch CS, Portera L, Hartwell N, Iqbal MI (1997) Lower risk of suicide during pregnancy. Am J Psychiatry 154:122-123

47. Appleby L (1991) Suicide during pregnancy and in the first postnatal year. BMJ 302:137-140

48. Wallace ME, Hoyert D, Williams C, Mendola P (2016) Pregnancy-associated homicide and suicide in 37 US states with enhanced pregnancy surveillance. Obstet Gynecol 215:364

49. Lund C, Breen A, Flisher AJ, Kakuma R, Corrigall J, Joska JA, Swartz L, Patel V (2010) Poverty and common mental disorders in low and middle income countries: a systematic review. Soc Sci Med 71:517-528

50. Gelaye B, Rondon MB, Araya R, Williams MA (2016) Epidemiology of maternal depression, risk factors, and child outcomes in low-income and middle-income countries. Lancet Psychiatry 3:973-982

51. Lund C, De Silva M, Plagerson S, Cooper S, Chisholm D, Das J, Knapp M, Patel V (2011) Poverty and mental disorders: breaking the cycle in low-income and middle-income countries. Lancet 378:1502-1514

52. Patel V, Lund C, Hatherill S, Plagerson S, Corrigall J, Funk M, Flisher AJ (2010) Mental disorders: equity and social determinants. Equity Soc Determ Public Health Program 115:34

53. Dewing S, Tomlinson M, le Roux IM, Chopra M, Tsai AC (2013) Food insecurity and its association with co-occurring postnatal depression, hazardous drinking, and suicidality among women in peri-urban South Africa. J Affect Disord 150:460-465

54. Huddleston-Casas C, Charnigo R, Simmons LA (2009) Food insecurity and maternal depression in rural, low-income families: a longitudinal investigation. Public Health Nutr 12:1133-1140

55. Arndt C, Robinson S, Gabriel S (2020) Who has been hit hardest by South Africa's lockdown? We found some answers. DownToEarth. https://www.downtoearth.org.in/blog/economy/whohas-been-hit-hardest-by-south-africa-s-lockdown-we-found-someanswers-71733. Accessed 11 Sept 2020

56. Statistics South Africa (2020) Results from Wave 2 survey on the impact of the COVID-19 pandemic on employment and income in South Africa. Department of statistics South Africa. http://www. statssa.gov.za/publications/Report-00-80-03/Report-00-80-03May 2020.pdf. Accessed 11 Sept 2020

57. Malan M, Spedding MF, Sorsdahl K (2018) The prevalence and predictors of intimate partner violence among pregnant women attending a midwife and obstetrics unit in the Western Cape. Global Mental Health 5:e18

58. Schneider M, Baron E, Davies T, Munodawafa M, Lund C (2018) Patterns of intimate partner violence among perinatal women with depression symptoms in Khayelitsha, South Africa: A longitudinal analysis. Global Mental Health 5:e13 